\title{
Palavra Divina ou palavra humana?
}

\section{Divine Word or human word?}

\author{
Mario de França Miranda*
}

Recebido em: 08/05/2020. Aceito em: 25/05/2020.

Resumo: O texto trata da noção de Palavra de Deus numa perspectiva de teologia fundamental, apresentando a problemática subjacente a esta expressão, abordando a pessoa de Jesus Cristo como Palavra definitiva de Deus na história e elencando algumas consequências para a vida da Igreja.

Palavras-chave: Teologia fundamental. Revelação. Palavra de Deus.

Abstract: The text deals with the notion of the Word of God in a perspective of fundamental theology, presenting the problems underlying this expression, addressing the person of Jesus Christ as the definitive Word of God in history and listing some consequences for the life of the Church.

Keywords: Fundamental theology. Revelation. God's word.

\section{Introdução}

Foi-me pedido para escrever sobre a Palavra de Deus. Certamente um tema bastante abrangente e complexo, como se pode constatar da Exortação Apostólica Pós-Sinodal Verbum Domini do Papa Bento XVI. Neste texto aparece claramente como este tema abarca praticamente todos os setores da vida cristã, não se limitando apenas ao âmbito da Sagrada Escritura, mas atingindo setores como Igreja, liturgia, moral, sacramentos, ecumenismo, religiões, culturas, justiça, espiritualidade. Diante deste fato tivemos que optar para uma perspectiva mais limitada de leitura deste vasto tema, a saber, por uma ótica mais própria da teologia

* Doutor em Teologia (Pontifícia Universidade Gregoriana, Roma, Itália, 1974). Mestre em Teologia (Faculdade de Teologia da Universidade de Innsbruck, Áustria, 1968). Graduado em Filosofia (Faculdade de Filosofia Nossa Senhora Medianeira, 1962). Professor associado da Pontifícia Universidade Católica do Rio de Janeiro. Lattes: Lattes: 1785242776254374.

E-mail: mfranca36@gmail.com; mfranca@puc-rio.br. 
fundamental ao refletir sobre a base antropológica do que conhecemos como "Palavra de Deus".

Deste modo seguimos uma tendência, já observada na teologia dos últimos anos devido ao surgimento da assim chamada "modernidade" que, embora em crise devido a diversos fatores (pós-modernidade), continua dominando o imaginário coletivo da atual sociedade. O choque da fé cristã com a modernidade tem início exatamente com os estudos bíblicos, basta que lembremos o nome do Padre Lagrange e o que ele teve de sofrer no início do século XX. Contudo foi na metade desse século que a construção teológica, mais conhecida como a "escolástica" começa a sofrer críticas provenientes de pesquisas bíblicas e históricas, abrindo assim caminho para uma renovação da tradição cristã que mostrará seus frutos no Concílio Vaticano II.

Esta corrente de pensamento ficou conhecida como a "virada antropológica" na teologia católica. Indaga-se assim pelo fundamento no próprio ser humano que explique, capacite, oriente este mesmo ser humano a acolher verdades e realidades oferecidas pela fé cristã. Consequentemente se questiona a visão dualista que separava natureza e graça, natural e sobrenatural, que, correta na sua intenção, provocou consequências nefastas para o cristianismo, ao isolar a esfera sagrada do cotidiano real dos fiéis, propiciando assim o que mais tarde se chamaria o fenômeno da secularização, e ao mesmo tempo enfatizando demasiadamente a pastoral sacramental e devocional.

Reconhecer a unidade da natureza e da graça significa reconhecer que a ação salvífica de Deus atinge o ser humano em todos os âmbitos de sua existência e que igualmente a resposta da pessoa poderá acontecer fora do setor "sagrado". Deste modo se valoriza o que constitui a vida real de cada um, vida familiar, profissional, cultural, social, política, etc. Nenhum desses setores vitais deixa de ser atingido pela ação salvífica de Deus. Com outras palavras, todos eles podem mediatizar a resposta humana à iniciativa de amor de Deus. Assim se abriu a possibilidade da teologia das realidades terrestres, entre as quais na América Latina as teologias da libertação.

Nesta mesma linha se indaga pelos pressupostos que facilitam o acolhimento das verdades cristãs, setor próprio da teologia fundamental. Se o ser humano é um ser que necessariamente produz símbolos, então melhor se entende os sacramentos como "sinais da graça". Se o ser humano percebe em si próprio uma abertura para o infinito, torna-se mais 
razoável a questão de Deus em sua vida. Se o ser humano só existe como ser social, sempre dependente de uma comunidade que lhe fornece os valores para que chegue à maturidade, então se explica a necessidade da Igreja. Se Deus que é transcendente, infinito, quiser se revelar de tal modo que possa ser entendido como tal pelos seres humanos, Ele deverá entrar na história como um ser humano. Naturalmente este fato implica não somente uma Kênose do Filho eterno do Pai, mas uma limitação inevitável devida à época histórica e ao contexto sociocultural escolhido. Também aqui o divino se encontra no humano, como já defendia o evangelista João contra os gnósticos.

Depois desta breve introdução fica mais fácil entender o objetivo deste texto. Examinar a base antropológica da própria revelação, no nosso caso, da Palavra de Deus como Palavra de Deus e não simplesmente como palavra humana sobre Deus, como pode se dar num horizonte de cunho filosófico, sociológico, histórico, psicológico, ou cultural. Esta afirmação não exclui tais campos do saber da compreensão estritamente teológica, a saber, da inteligência que brota da própria fé, como veremos adiante.

\section{A Palavra de Deus como problema}

Realmente ao afirmar "Palavra de Deus" estamos trazendo à superfície um sério problema, pois imaginamos inconscientemente que o agir de Deus é semelhante ao agir humano. Consequentemente o ser humano poderia captar esta ação divina e simplesmente enunciá-la para os demais. Porém captar o agir de Deus significa captar o próprio Deus, pois em Deus ser e agir se identificam, e captar o infinito, o transcendente é impossível ao ser humano, cuja inteligência só pode conhecer o que é finito, limitado, que pode então ser "objeto" de seu conhecimento. E se Deus fosse tal, já não mais seria Deus, mistério último do ser humano, inacessível e indisponível, como nos demonstram os relatos bíblicos e a própria razão, já que o fundamento de toda a realidade finita não pode ser uma realidade limitada e ao alcance da inteligência humana.

E, contudo, não podemos negar que Deus possa intervir na história humana, já que dele depende toda a realidade. Se Ele intervém então o ser humano, de certo modo, deve conhecer tal ação divina, pois do contrário seria para ele simplesmente inexistente. Se Deus não pode se encontrar com o ser humano como um objeto de conhecimento ao lado de outros, Ele pode ser almejado pelo mesmo como um horizonte infinito para o 
qual tende a inteligência e a vontade humana. Aí Ele não é conhecido, mas pressentido, já que a pessoa tem dele certa consciência, seja como luz para a inteligência, seja como impulso para a liberdade.

Ter fé significa acolher esta ação de um Deus que se autocomunica ao ser humano sem que possamos fundamentar, visualizar, objetivar, esta mesma ação. Portanto a fonte última da nossa fé não pode ser diretamente objeto de um conhecimento humano que prescindisse da fé do sujeito. Com outras palavras, o fundamento a fé não se deixa novamente fundamentar. O que devemos ter presente, ponto sumamente importante, é que a iniciativa é de Deus, vem "de fora", não é produção meramente subjetiva. A fé não produz a Palavra de Deus, ela escuta, ela responde.

Deste modo estamos afirmando que a ação divina, mesmo sem ser objeto de conhecimento humano, goza de certa “objetividade", já que a nossa fé é sempre resposta a uma interpelação prévia de Deus. Tenhamos também muito presente que a ação divina é interpelação à liberdade humana, pois sua finalidade é de ordem salvífica: Deus vem ao encontro do ser humano para salvá-lo, isto é, para fazê-lo participar de sua vida e de sua felicidade: ao procurar nos salvar, Ele se revela. A "economia" precede a "teologia". Consequentemente Palavra de Deus jamais será tal para alguém que busque conhecê-la sem a menor preocupação salvífica, apenas como objeto de conhecimento e de estudo.

Ter fé significa assim acolher livremente esta interpelação de Deus como de Deus. Como está lidando com o mistério infinito que não se deixa ser contido, e assim conhecido pela limitada inteligência humana, o gesto de Deus só poderá ser realmente salvífico através da livre opção de fé. O mistério de Deus deixa espaço para a liberdade, pois o que é racionalmente certo e provado já não pode ser objeto da fé.

Por outro lado a ação salvífica de Deus, mesmo sem ser objeto de conhecimento humano, atinge o centro da pessoa, seu coração na linguagem bíblica, onde as faculdades constituem uma unidade (inteligência, liberdade, afetividade, imaginação, memória), de tal modo que, como dissemos, a pessoa tem dela certa consciência, mas não um conhecimento objetivo. Ao procurar captar, entender, expressar esta ação divina o ser humano irá necessariamente torná-la objeto de conhecimento, que não é propriamente Palavra de Deus, mas representação (objetivação) da mesma.

O que conhecemos como a Bíblia constitui a sedimentação de tais representações já como objetos de conhecimento e que nos remetem à 
Palavra de Deus que as originou. São objetivações necessárias, pois nelas e através delas Deus se autocomunica, mas são também inadequadas por não se identificarem com sua fonte. Pelo fato de serem expressas pelo ser humano sempre inserido num contexto histórico e sociocultural, tais condicionamentos estarão também presentes nos desafios concretos, na linguagem, na concepção do mundo, abrindo assim a possibilidade de serem tais representações revistas e atualizadas para outros contextos, pois a ação salvífica de Deus não se interrompe e os sujeitos que a recebem já são outros.

Entretanto como as representações da Palavra de Deus na Bíblia apresentam para o fiel a verdade da revelação, embora na roupagem limitada da linguagem humana, elas permanecem como referências não descartáveis da Palavra de Deus. A aplicação destas representações a outros contextos e épocas demonstra a potencialidade da Palavra de Deus em se fazer presente e pressentida por toda parte e por todo tempo.

As expressões da Palavra de Deus, enquanto produzidas pelo ser humano, explicam também a diversidade dos gêneros literários encontrados na Bíblia, conforme os destinatários da ação divina conseguiram representá-la. Também explica porque gerações posteriores de fiéis possam crescer na compreensão destas representações por disporem de outras óticas de leitura, por enfrentarem novos desafios, por experimentarem a ação de Deus mais profundamente, como reconheceu o Concílio Vaticano II $^{1}$. Naturalmente ao afirmamos que a ação salvífica de Deus acontece "através de acontecimentos e palavras intimamente conexos entre si" 2 , também estes eventos históricos deverão passar pela mediação da fé do cristão para que sejam entendidos como ação de Deus, e não apenas como meros eventos históricos.

\section{Jesus Cristo como Palavra de Deus}

O evangelista João afirma que "a Palavra se fez carne e veio morar entre nós" (Jo 1,14) e o autor da Carta aos Hebreus diz que "muitas vezes e de muitos modos, Deus falou outrora aos nossos pais, pelos profetas. Nestes dias, que são os últimos, falou-nos por meio do Filho"

1 CONCÍLIO VATICANO II, 1962-1965, Vaticano. Constituição Dogmática Dei Verbum. Vaticano, 1965. 8. ed. São Paulo: Paulinas, 2003. DV 8.

2 Dei Verbum, n. 2. 
(Hb 1,1s). A presença salvífica da própria Palavra de Deus na história humana constitui um evento inédito na caminhada do Povo eleito rumo ao Reino de Deus. Enquanto Palavra de Deus ela é única e definitiva; enquanto Palavra de Deus num ser humano ela inevitavelmente será captada, entendida e expressa no interior dos condicionamentos próprios à condição humana.

A novidade aqui é que esta Palavra de Deus se encontra na história de Jesus de Nazaré, tanto em suas palavras quanto em suas ações, como afirma Bento XVI: “Aqui a Palavra não se exprime primariamente num discurso, em conceitos ou regras, mas vemo-nos colocados diante da própria pessoa de Jesus. A sua história, única e singular, é a palavra definitiva que Deus diz à humanidade"'. Ao afirmar esta verdade não dizemos que a pessoa de Cristo proporciona já um conhecimento objetivo do que caracterizamos até aqui como Palavra de Deus, pois neste caso destruiríamos a transcendência e o mistério de Deus afirmado no Antigo Testamento.

Como explicar esta questão? Por um lado Jesus Cristo foi em toda sua vida perfeitamente conforme a ação de Deus: "Aquele que me enviou, está comigo. Ele não me deixou só, porque eu sempre faço o que é de seu agrado" (Jo 8,29). Sabemos que o cumprimento desta obediência teve momentos críticos, mas que não desviaram Jesus de sua fidelidade ao Pai: "que não se faça a minha vontade, mas a tua" ( $\operatorname{Lc} 22,42)$. Deste modo podemos afirmar que toda a história de Cristo, ações e palavras, é revelação de Deus, é Palavra de Deus, e Palavra definitiva por ser a própria Palavra de Deus humanizada. Daí poder Ele afirmar: "Felipe, quem me viu, viu o Pai" (Jo 14,9).

Por outro lado, por ser Palavra de Deus, o Filho de Deus, o próprio Deus que veio participar da condição humana, a pessoa de Jesus Cristo permanece sempre um mistério para o conhecimento humano. Sua pergunta "Quem dizem os homens que eu sou?" (Mc 8,27) não consegue ser respondida adequadamente pela inteligência humana. Ela só pode ser esclarecida à luz da fé que já implica um "upgrade" da razão sob a ação do Espírito Santo (1Cor 12,3). Como já se escreveu: só Deus pode nos fazer conhecer Deus! E mesmo para os cristãos a pessoa de Cristo jamais poderá ser reduzida a conceitos humanos e finitos, e assim sujeita ao conhecimento humano como simples objeto.

3 BENTO XVI. Exortação Apostólica Pós-Sinodal Verbum Domini. Vaticano: Libreria Editrice Vaticana, 2010. VD n. 11. 
As abordagens desta Pessoa, desta Palavra de Deus, são sempre históricas, realizadas sempre dentro de um contexto histórico e sociocultural bem determinado que inevitavelmente a consideram sob o seu ponto de vista próprio. E como diferentes chaves de leitura ou horizontes culturais nos abrem novos conhecimentos da realidade, assim também elas possibilitam esta sucessão de cristologias, todas imperfeitas por serem leituras humanas de um personagem divino.

E ainda devemos considerar mais um dado importante para o nosso tema. Ao caracterizar Deus como amor e afirmar que quem ama conhece a Deus (1Jo 4,8.16), o evangelista João afirma que quanto mais se vive a própria fé, maior conhecimento tem o cristão da Palavra de Deus ${ }^{4}$. No caso da Palavra de Deus humanizada, a saber, da pessoa de Jesus Cristo, isto implica sintonia de vida com a vida do Mestre de Nazaré, que possibilita um conhecimento de cunho não apenas nocional, mas também existencial ou místico, como podemos verificar na vida de tantos santos e tantas santas da Igreja. O autêntico discípulo de Cristo é animado pelo mesmo Espírito que atuou na pessoa do Messias, levando-o a uma conformação maior com sua vida e uma inteligência maior da Palavra de Deus encarnada. Quando Paulo afirma que o cristão deve viver segundo o impulso do Espírito (Gl 5,25), este é o Espírito do Filho $(\mathrm{Rm} 8,9)$, que atinge o núcleo profundo do cristão, portanto também sua liberdade e sua afetividade.

Como no Antigo Testamento devemos nos voltar para as sedimentações da ação salvífica de Deus que nos mediatizam de modo humano a revelação divina, assim também é através da humanidade de Jesus que podemos perceber a ação salvífica do Filho de Deus. Como diz um texto do Concílio Vaticano II: "Deus na Sagrada Escritura falou através de homens e de modo humano" . Daí a importância de sua história, de suas palavras, de seus gestos, de seu comportamento, do seu modo de olhar pessoas e de avaliar acontecimentos, pois todos esses dados são revelação de Deus, Palavra de Deus. Consequentemente toda a vida de Jesus é uma interpelação constante à nossa liberdade e não apenas objeto de conhecimento. Pois é a encarnação em nossa história de um Deus, não somente mistério transcendente, mas amor que se entrega a nós (Jo 3,16).

\footnotetext{
4 Dei Verbum, n. 30.
}

5 Dei Verbum, n. 12. 
Ainda uma importante verdade. A Palavra de Deus é dirigida a um povo e é acolhida na fé por um povo ${ }^{6}$. Sabemos que as tradições orais na Igreja Primitiva precederam e possibilitaram os textos evangélicos. O que era vivido suscitou o que foi posteriormente escrito. Pois toda Palavra de Deus não é apenas palavra, pois provem do Deus que é amor, que vem ao encontro de sua criatura, que interpela e provoca uma resposta, a saber, é uma Palavra atuante. O mesmo se pode dizer da Palavra que é Jesus Cristo. O povo que $\mathrm{O}$ acolheu fez da Palavra de Deus uma Palavra não só conhecida, mas vivida.

Portanto a plenitude da Palavra de Deus acolhida se encontra na fé de todo o povo de Deus cunhada na expressão "sentido da fé" (sensus fidei). Como afirma um texto conciliar: "Assim a Igreja, em sua doutrina, vida e culto, perpetua e transmite a todas as gerações tudo o que ela é, tudo o que crê"’ . Assim podemos afirmar que a Palavra de Deus se encontra mais plenamente na vivência de fé da Igreja universal do que nas próprias expressões da teologia e do magistério eclesiástico. Mesmo o que chamamos de "depósito da fé" (depositum fidei), quando entendido como uma grandeza pétrea e intocável, se revela uma expressão insuficiente, pois constitui já uma objetivação de uma realidade mais ampla, como reconhece o próprio texto conciliar acima citado ao afirmar que "a Igreja no decorrer dos séculos tende continuamente para a plenitude da verdade divina" ${ }^{8}$. Este fato não exclui a normatividade deste patrimônio da fé, mas permite que o mesmo receba novos enriquecimentos.

Se a fé cristã é essencialmente teológica por se dirigir ao próprio Deus, ela é, em sua modalidade, eclesiológica. A fé do cristão é sempre participação na fé da Igreja. Desrespeitar esta verdade significa abandonar a Palavra de Deus a interpretações subjetivas e inconsistentes, às vezes das mais estapafúrdias, que fragmentam e que desacreditam o próprio cristianismo, fato este agravado hoje pela impossibilidade de ter o controle de suas verdades por parte da Igreja. A leitura da Bíblia a partir de perspectivas estranhas (até financeiras!) à fé cristã gera os maiores disparates sobre a pessoa e a mensagem de Jesus Cristo, como vemos em nossos dias.

\footnotetext{
6 Verbum Domini, n. 30.

7 Dei Verbum, n. 8.

8 Dei Verbum, n. 8.
} 


\section{Consequências para a vida da Igreja}

Em primeiro lugar surge a questão da inculturação da fé que, no fundo, versa sobre a inculturação da Palavra de Deus. De fato, enquanto Palavra de Deus na mediação necessária da palavra humana, estará esta Palavra de Deus sujeita aos condicionamentos de cunho histórico e sociocultural daqueles que a recebem, entendem e vivem. Outros horizontes culturais, outros contextos vitais, exigirão que a mesma seja expressa, objetivada, vivida em sintonia com os mesmos. Caso contrário, ela não mais será pertinente, a saber, palavra que interpela e que oferece sentido e salvação, simplesmente por não ser captada como tal.

Tarefa complexa a ser realizada pelos próprios nativos de uma cultura que ao se defrontarem com a mensagem evangélica anunciada já em outra cultura deverá procurar entendê-la e vivê-la a partir de sua própria realidade. Tarefa complexa como nos ensinam as heresias cristológicas e trinitárias dos primeiros séculos do cristianismo, quando aconteceu a primeira e mais importante inculturação da fé na história do cristianismo. Tarefa complexa que deverá ser realizada ao longo do tempo, no diálogo com outras culturas e na abertura a correções. Tarefa complexa, mas que irá enriquecer sobremaneira o próprio cristianismo com novas sedimentações da Palavra salvífica de Deus.

Subjacente a toda esta reflexão está uma distinção, ainda não mencionada, mas sempre presente neste estudo. A ação de Deus em sua Palavra pode ser caracterizada como uma realidade "teologal" que só chega a seu destinatário como realidade "teológica", a saber, captada, expressa e vivida, enquadrada assim numa linguagem e num contexto vital humano. Consequentemente todas as confissões de fé enquanto situadas no plano das objetivações humanas estão sujeitas aos condicionamentos próprios da condição humana: estão determinados por fatores históricos, culturais, linguísticos, etc.

Portanto a persistência em manter confissões de fé do passado nas celebrações litúrgicas pouco aproveita ao povo de Deus por apresentarem problemas e expressões já ultrapassadas que não são mais entendidas. A Igreja deveria aproveitar a riqueza dos estudos bíblicos em curso para apresentar sua fé numa perspectiva histórico-salvífica de mais fácil alcance pelo povo de Deus do que expressões de cunho ontológico, mesmo reconhecendo sua verdade. 
Enquanto a Palavra de Deus traduz a própria ação salvífica de Deus que é universal, a saber, não se limita ao interior do cristianismo, ela alcança todos os povos e todas as culturas da terra através da atuação do Espírito Santo. A encíclica A Missão do Redentor de João Paulo II afirma que "a presença e ação do Espírito não atingem apenas os indivíduos, mas também a sociedade e a história, os povos, as culturas e as religiões" Tal ação quando percebida e acolhida oferecerá expressões tanto culturalmente quanto religiosamente dependentes do contexto próprio onde se encontra o indivíduo. Embora diversas das expressões tradicionais, que nos são familiares, podem elas conter elementos do patrimônio cristão, embora numa linguagem diferente.

O importante aqui não são tanto as expressões, quanto a força salvífica das mesmas que possibilita membros de outras religiões responderem à iniciativa divina com os recursos disponíveis, sejam culturais, sejam religiosos. A experiência recolhida por aqueles que se dedicam ao diálogo inter-religioso confirma este fato. Pois a modalidade deste diálogo que trouxe maiores frutos não foi a que se desenrolava no âmbito das reflexões teológicas ou das ações comuns pela justiça, mas naquela que implicava troca das experiências subjacentes às suas próprias convicções religiosas, ainda que expressas diversamente.

Outra consequência do que vimos diz respeito à evolução do que se entende por Palavra de Deus, evolução esta inerente à sua própria compreensão por parte do cristianismo. Pois jamais chegaremos à plenitude da verdade divina, como observa Paulo $(1$ Cor 13,12$)$ e reafirma o documento Diálogo e Anúncio ${ }^{10}$, pois todo discurso humano sobre Deus é um discurso inacabado que percebe a verdade divina enquanto tende para a mesma, como observa Tomás de Aquino (S.Th. II-II, q.1, a.6, sed contra). Pois o mistério de Cristo, Palavra de Deus, excede as possibilidades de expressão de qualquer época, estando ligado ao caminhar histórico da Igreja e recusando ser fixado num sistema atemporal, no fundo limitado a quadros interpretativos transitórios.

Esta afirmação de cunho teológico é confirmada por outra de âmbito antropológico. Pois todo conhecimento acontece no interior de um quadro interpretativo (horizonte de compreensão), os quais se sucedem

9 JOÃO PAULO II. Carta Encíclica Redemptoris Missio sobre a missão do Redentor. São Paulo: Paulinas, 1991. n. 28.

10 PONTIFÍCIO CONSELHO PARA O DIÁLOGO INTER-RELIGIOSO. Diálogo e Anúncio. 4. ed. São Paulo: Paulinas, 1999. n. 49. 
ao longo da história, modificando os anteriores. O conhecimento humano pressupõe sempre uma pergunta à qual responde então a realidade revelando sua verdade. Deste modo novas questões surgidas na história humana significam também novas perspectivas de leitura para uma maior compreensão da Palavra de Deus. Afirmar que a Palavra de Deus foi pronunciada definitivamente em Jesus Cristo não exclui que a expressão de sua verdade possa se desvelar ao longo da história.

Desde que a Palavra de Deus é acolhida na fé e vivida no cotidiano por todo o Povo de Deus ela será certamente enriquecida em sua compreensão pela participação de todos em suas expressões e práticas. Neste sentido esta tarefa não deve ser monopólio do clero, mas tarefa comum também de leigos e de leigas, pois estes a vivem em situações alheias à esfera de contato e de ação do clero, enfrentando outros desafios e recorrendo a novas linguagens para expressar o que creem e o que vivem. A compreensão da Palavra de Deus certamente seria mais plena e mais próxima à vida dos fiéis.

\section{Referências}

BENTO XVI. Exortação Apostólica Pós-Sinodal Verbum Domini. Vaticano: Libreria Editrice Vaticana, 2010.

COMISSÃO TEOLÓGICA INTERNACIONAL. Opluralismo teológico. São Paulo: Loyola, 2002. n. 17.

CONCÍlIO VATICANO II, 1962-1965, Vaticano. Constituição Dogmática Dei Verbum. Vaticano, 1965. 8. ed. São Paulo: Paulinas, 2003.

ESTRADA, Juan A. Qué decimos cuando hablamos de Dios? Madrid: Trotta, 2015. p. 91-125.

HAIGHT, Roger. Dinâmica da Teologia. São Paulo: Paulinas, 2004. p. 149-167.

JOÃO PAULO II. Carta Encíclica Redemptoris Missio sobre a missão do Redentor. São Paulo: Paulinas, 1991.

MIRANDA, Mario F. A difícil inculturação da fé. In: HACKMANN. Geraldo L. B. (Org.). Sub umbris fideliter. Festschrift em homenagem a Frei Boaventura Kloppenburg. Porto Alegre: EDIPUCRS, 1999. p. 287-306.

MIRANDA, Mario F. A Igreja numa sociedade fragmentada. São Paulo: Loyola, 2006. p. 297-314. 
PESCH, Otto H. Das Wort Gottes als objektives Prinzip der theologischen Erkenntnis. In: KERN. Walter; POTTMEYER, Hermann J.; SECKLER. Max. (Hrsg.). Handbuch der Fundamenaltheologie IV: Traktat theologische Erkenntnislehre. Freiburg: Herder, 1988. p. 37-41.

PONTIFÍCIO CONSELHO PARA O DIÁLOGO INTER-RELIGIOSO. Diálogo e Anúncio. 4. ed. São Paulo: Paulinas, 1999. 